\title{
PRINCIPLES FOR AEROSPACE MANUFACTURING ENGINEERING IN INTEGRATED NEW PRODUCT INTRODUCTION
}

\author{
Malachy Maginness ${ }^{1}$, Essam Shehab ${ }^{1}$, Chris Beadle ${ }^{2}$ and Matt Carswell ${ }^{2}$ \\ ${ }^{1}$ Product and Service Innovation Centre, Manufacturing and Materials Department, Cranfield \\ University, Cranfield, Bedfordshire, MK43 OAL, United Kingdom \\ ${ }^{2}$ Rolls-Royce plc., PO Box 31, Moor Lane, Derby, DE24 8BJ, United Kingdom
}

\section{Abstract}

This paper investigates the value-adding practices of Manufacturing Engineering for integrated New Product Introduction (NPI). A model representing how current practices align to support lean integration in Manufacturing Engineering has been defined. The results are used to identify a novel set of guiding principles for integrated Manufacturing Engineering. These are: (1) Use a data-driven process; (2) Build from core capabilities; (3) Develop the Standard; (4) Deliver through responsive processes; and (5) Align cross-functional and customer requirements.

The investigation used a mixed-method approach. This was comprised of case studies to identify current practice and a survey to understand implementation in a sample of component development projects within a major aerospace manufacturer. The research contribution is an illustration of aerospace Manufacturing Engineering practices for New Product Introduction. The conclusions will be used to indicate new priorities for NPI and the cross-functional interactions to support flawless and innovative NPI. The final principles have been validated through a series of consultations with experts in the sponsoring company to ensure correct and relevant content has been defined.

Keywords: New Product Introduction, Manufacturing Engineering, Aerospace, Lean

\section{Introduction}

This work explores aerospace Manufacturing Engineering (ME) practices for integrated New Product Introduction (NPI). NPI is the cross-functional product development process used by global aerospace manufacturers to deliver all customer and business expectations for quality, cost effectiveness and lead time. Integration is the close coordination of different functional processes for the purpose of ensuring all objectives and value adding activity are 
well aligned in the project. For Manufacturing Engineers, rigorous verification of production capability for all design features and the creation of detailed production plans are important value-add activities. These traditionally require stable designs whereas managing an evolving design maturity is the important ability for integrated product development.

The trend in aerospace is toward faster product introduction and rapid development cycles. A further requirement is flawless achievement of high quality products at the forefront of technical innovation. Integration and parallel processes for design and manufacturing are valuable for satisfying both these imperatives and are strongly advocated in research literature.

In the last decade a range of practice has been developed for the process, organisation and tools to support integration. It is valuable to understand how Manufacturing Engineers currently manage integration and to build on this experience to support an escalating quantity, scale, and frequency of future product introduction. Furthermore, the research literature lacks a comprehensive understanding of integrated ME activities to deliver production planning in parallel with design processes.

This paper presents the results of a mixed-method investigation to address this gap that was conducted with the support of the industrial sponsor, a global aerospace manufacturer operating in the United Kingdom. The objectives were to: investigate ME practices for integrated NPI; survey the use of the practices aerospace component NPI projects in the company; identify how the practices work together for lean product development; and define a set of guiding principles for aerospace ME in integrated NPI.

The article is structured as follows. A discussion of the literature related to integrated product development and ME is presented in Section 2. The mixed-method research approach that has been used is described in Section 3. In Section 4 a review of ME practices for NPI in the industrial context is presented. In Section 5 principles to support integrated ME are defined and used to understand opportunities to improve performance of NPI. Section 6 offers conclusions.

\section{Related Work}

Cross-functional integration, or Concurrent Engineering, has been established as a requirement for competitive product development in over two decade's research literature. Managing parallel processes with rich and bilateral exchanges of cross-functional information are now the fundamental competencies that support effective decision-making 
[1-3]. These are competences that supersede 'over-the-wall' and 'silo' forms of product development associated with unsustainable misalignment of objectives shared across functions. How information is created and shared has been the research focus in this domain in the last two decades. Research in the initial period of literature (covering the last decade of the $20^{\text {th }}$ Century) focussed on good practice for enabling cross-functional integration. The role and responsibilities of Manufacturing Engineering are described in this literature. A second period of literature (in the first decade of the new century) has focussed on the lean product development system as further means of overcoming complexity and barriers. It is the 'lean' product development domain where understanding efficient and effective operation of Manufacturing Engineering is less clear.

From the outset of literature related to Concurrent Engineering, the integration of processes for design and manufacturing is explored as an important dynamic for successful product development [4]. Categories of practice including process, organisation and tools are described strongly in the literature for enabling cross-functional integration. Engineering processes for design and manufacturing that are initiated in parallel from the start of the development lifecycle are a key characteristic in integrated projects [1]. Parallel creation of information in these processes, shared in 'Design for Manufacture' dialogue, overcomes restrictions in decision-making [5]. Incorporating manufacturing and assembly capability information is invaluable for influencing a concept that can be produced at desired quality and cost levels. Without close integration, rework to align design objectives with those of manufacturing carries a high penalty in cost and time [6]. Also, Manufacturing Engineers can plan production in parallel to enable more immediate production ramp-up and shorten overall project time [7]. However, for parallel processes, using partial and incomplete design definition should be prioritised over full definition and Manufacturing Engineers must avoid a 'hostile' attitude to using such information [1]. Organisation and, in particular, crossfunctional teams are crucial for achieving information sharing that is rich and frequent [7-8]. Heavyweight leadership, autonomy and physical co-location are among the valuable characteristics for successful teams [9-12]. Other studies examine the importance of tools (particularly computer technologies) that are used for sharing engineering information. In contrast to paper-based tools, computer-aided design (CAD) brings speed and accuracy benefits to the creation, rework and sharing of complex design and manufacturing definitions, and automation and simulation opportunities [13-14]. Information tools are also useful for process integration: by building from a CAD model definition shared from designers, Manufacturing Engineers can ensure accurate adherence to design intent when developing computer-aided manufacturing (CAM) solutions [4, 13]. Information systems are 
identified as important for global product development teams for which co-location is replaced by 'virtual' teams. Here communication is maintained by file sharing, email and telecommunications [15].

In recent literature the lean product development concept has been identified. This work is focused on principles for lean product development and also process mapping techniques to support process re-structuring [16-19]. Lean principles for product development have been devised based on lean in physical operations [20-22].

Value in product development processes can be enhanced by improving the flow of 'partial' product information [23]. Large batches of 'completed' information leads to large downstream work batches. This has implications for evaluation of design information. If evaluation is conducted only for completed designs this will become a large batch of work and thus diminish the effectiveness of manufacturing influence with cross-functional partners. A virtuous iteration can be derived from early, bilateral feedback that ultimately shortens development time.

Despite the literature for lean product development (meaning Design Engineering) there has been little work done to address a second aspect of efficient new product introduction, specifically, lean process development (Manufacturing Engineering) [24, 25]. There is a widely held view that set-based concurrent engineering (SBCE) is an enabling technique for lean product development [26-28]. SBCE allows manufacturing options to be used to progressively influence the design and narrow toward a final solution whilst, crucially, delaying this fixed commitment as long as possible. However, this approach limits attention to the role of Manufacturing Engineers for the conceptual stage only.

Lean product development literature is a promising area of research. Nevertheless, it continues to lack a clear understanding of manufacturing process planning and concurrency beyond the conceptual stage of the lifecycle and into downstream stages for physically realising the production method. Two key gaps in the research can be identified. The first is a clear understanding of ME practices and how they work together as a value-adding system for lean product development. A second gap are principles for successful ME integration with the cross-functional organisation that achieves not only parallel evaluation, but also delivery of the production method. 


\section{Research Methodology}

An inductive methodology was followed for the explorative study. Figure 1 depicts the mixedmethod approach consisting of case studies and a survey that was used to satisfy research objectives [29].

\section{Insert here:}

\section{Figure 1 The mixed-method investigation used to satisfy research objectives}

The initial literature review served to refine the scope for data collection and analysis [31, 31]. The definition of 'current practice' included process activities (inputs and outputs), tools used and organisational concepts (what personnel or roles were involved). Units of analysis were defined through discussions with stakeholders and familiarisation with company literature. The unit of analysis comprised: activities for manufacturing process planning and quality planning; executed by a ME business; for a specific component from a gas turbine development project.

The investigations were conducted using this unit of analysis with direct engagement of manufacturing locations of the aerospace industrial sponsor. Selection was coordinated with stakeholders and business managers and each component NPI project was contemporary to the research period. Data collection was carried out using semi-structured and structured interviews (for cases and survey) and workshops (case studies only). Interview results were triangulated with materials including project plans and company process literature. Question sets were piloted with subject experts. All data collection drew on Manufacturing Engineer practitioners in businesses who apply the processes.

For the case studies a one hour semi-structured interview question set was used. This was based around the categories on a SIPOC chart (Supplier-Input-Process-Output-Customer). Interview data was analysed through the creation of role-activity process maps. Next a comprehensive review and categorising ME practices according to a 'Process', 'Organisation' and 'Tools' model was carried out. Case studies were carried out April to November 2011. The survey was conducted March to August 2012. A one hour structured question set was developed for the survey using case study results. For each survey at least one or two NPI leaders were directly interviewed and asked to characterise (score) the strength at which described practices are applied for the unit of analysis. The scores defined were: 0 - this practice occurs almost never ( $<10 \%$ frequency); 1 - this practice occurs mostly 
not ( 25\%); 2- intermediate occurrence (50\%); 3 - this practice occurs for the most part ( $75 \%)$; 4- this practice occurs routinely (>90\% frequency).

The mixed-method approach was used to build internal validity. The case studies first enabled a detailed investigation and the subsequent survey allowed an efficient means of verifying this understanding across the broader organisation for NPI. The final sample comprised $14 \mathrm{NPI}$ examples (two detailed process mapping case studies followed by 12 surveys). A range of specialised production methods are applied for realising aero engine components that differ in the range of materials used and design complexity. However, a description of practice for specific component or technology examples is not provided in this paper. Instead, the intention is to describe the general understanding of current practice.

The completed investigation resulted in identification of current practices and how these add value in aerospace ME NPI. Finally these were used to identify factors that explain 'why' identified practices benefit the performance of NPI. These would be used as the guiding principles. Using brainstorming charts the practices were first grouped into an initial set of factors according to their shared affinities. Finally, semi-structured consultations with stakeholders in the research, and subject experts in the business were conducted to validate final principles.

\section{Manufacturing Engineering Practices}

The case studies and survey results provide a rich account of ME practice for integrated NPI projects. To address the first research gap the results are used to create the summary model shown in Figure 2.

\section{Insert here:}

\section{Figure 2 The alignment of Manufacturing Engineering practices to add value in NPI}

Two main forms of value creation are demonstrated in the model. Firstly, Manufacturing Engineers add value to a design by planning (creating all information that defines the manufacturing and inspection method). This information includes the method of manufacture (operations list), stage definitions (geometry created from each operation), fixture tools and machining programmes. Secondly, Manufacturing Engineers also add value through evaluation (creating information to verify the capability of creating or inspecting design features). 
The model depicts the alignment and interaction of practices in process, organisation and tool categories that are important to value creation at different stages of the lifecycle. The following sections describe the alignment indicated by the model and reports contextual factors related to implementation that were indicated by the survey.

\subsection{Process}

The integrated process can be explained with the following distinct practices: progressive activities; using knowledge; and change in the process.

The key requirements of Manufacturing Engineers is progressive definition that supports lead times and to also control the risk of change in detailed planning and high value tasks. An early concept definition is used to understand the method of manufacture and clarify downstream planning need (using the team-based organisation). Later, preliminary definition is used to initiate long lead time activities (such as procurement of material), and to model 'roughing' operations. Finally, a fixed definition (which includes tolerances and detailed geometry) is necessary for modelling 'finishing' operations, fixture tools, and machine programmes. The fixed definition indicates the design is stable, that manufacturing geometry will be unlikely to change and is necessary to launch high value production activity.

Manufacturing knowledge is used to reduce uncertainty in the development lifecycle in a number of areas. First, a standard method of manufacture for a component is used to drive early concept evaluation and to identify progressive release requirements. Furthermore, the design process is proactively front-loaded with a choice of 'production capable' features. Read-across of modular design (models) for fixture tooling development is also reported for accelerating completion. Lastly, feature-level capability data for existing production processes help progressive evaluation of production capability against concept and preliminary definitions. The objective is a progressively agreed 'production standard' definition with production capability verified for all features and all risks addressed. The survey responses indicate that the need for production trials (and associated restrictions in the project plan) is reduced for components where good feature capability data exists.

The risk of change in process planning is a characteristic of using unfinished definition. The survey investigated which activities are most affected by change. The results demonstrate that changes rarely occur for long lead time activities. Managing the effect of change in this way is valuable; changes here would risk project delivery. By contrast, the activities to model manufacturing operation geometry and machining programmes in the development stage 
are the activities most routinely affected by changes in design intent for the majority of sample components. However, iterations in these tasks align well with the tools used to carry them out, as will be described later.

\subsection{Organisation}

Component-level NPI projects are managed using cross-functional Integrated Product Teams (IPT). Communication is supported by collocation, direct visits between the functions and virtual communication. The IPT Leader is the primary point of contact between manufacturing and designers. The Manufacturing Engineer representative in the team ensures that manufacturing requirements are coordinated with other functions. The objective during the concept stage is to influence the design and gain commitment to the integrated project plan, and mitigate risks that would result in late definition release. In the development stage the objective is to coordinate with the IPT Leader to pull design definition in line with agreed plan. For the entire sample these requirements are agreed with the IPT Leader. It is notable that for components where the MLP was also agreed with designers (half of the sample) a release schedule that was accurate to the initial plan did successfully occur.

\subsection{Tools}

The tools used by Manufacturing Engineers are advantageous in different stages of the development lifecycle for supporting process activities and organisation.

In the development stage a standard computer-aided system is the primary tool for the planning activities. Computer models are used to link the parallel creation of design definition and all manufacturing definition. As noted above, these are often subject to revision in the development process. However, revisions are being directly cascaded through to all derivative models. This avoids the motion and transportation wastes otherwise associated with creating planning information across isolated systems.

Email, telephone communication and shared network folders helped good communication to be maintained for dispersed teams. A predominantly quantitative or data-driven dialogue is conducive for both for in-person and virtual interaction.

Procedures and tools for the routine collection of feature-level production capability data are identified as in place for all survey components. Information systems are deployed to capture and transfer this data from the shop floor and transmit it to ME offices for analysis. 
Additionally, virtual simulation tools are used to test the production method. In half the component survey virtual simulation tools are being applied to understand production capability. These serve to generate feedback that influences both manufacturing and design in a rapid manner requiring lower resource in comparison to full scale production trials. Machining is the main subject of virtual simulation found in the survey. There is an intermediate use of rapid prototyping for components in the sample. Applications include testing for clashes or collisions with fixtures tools, cutting tools, and machining paths. The physical impression of a component is also a useful input for Manufacturing Engineers.

\section{Principles for Manufacturing Engineering}

The results are used here to identify factors for successful Manufacturing Engineering integration with the cross-functional organisation. This is to address the second research gap. The method was to group practices into affinities. The result is the definition of Principles for Aerospace Manufacturing Engineering in Integrated New Product Introduction.

\subsection{Highlighting Key Factors}

The following describes five principles for delivering good NPI performance in quality, cost effectiveness and lead time that have been drawn from the current practice investigation:

\subsubsection{Using data-driven processes}

The underlying concepts that relate to 'use data-driven processes' are: supporting crossfunctional understanding and decision making; and capture and embed lessons.

\section{Supporting cross-functional understanding and decision making}

A data-driven process emphasises that decision making should be managed using good engineering data. Manufacturing Engineers use data that defines product design features (geometry and materials) and manufacturing capability. Data used brings rigour to the decision making for all aspects of NPI including the product, process and project plan and throughout the project lifecycle. Prioritising analysis using technical data provides for better understanding that tacit knowledge cannot support.

The superior ability for driving decision making that data gives ME and the integrated team was specified by the subject matter experts during the consultations. Data-driven processes for NPI support effective interactions with all cross-functional team members, for example, providing feedback of quantified manufacturing capability gaps. The influence that ME must 
have in the product team can also become more accurate through use of data. The datadriven form of dialogue is also applicable to virtual communication methods associated with the distributed organisation.

\section{Capture data and embed lessons}

As a project matures, new and more advanced manufacturing knowledge and process capability data will have been created. Recording this data is important so that it can be effectively used from the outset of the next project. The priority is to ensure lessons are learnt and applied to aid the next NPI project. In this way subsequent generations of product NPI can be better placed to drive decision making using data.

Procedures and tools for the routine collection of feature-level manufacturing capability data are identified. Information systems capture data from the shop floor and send it to ME for analysis that further supports ME responsiveness to Design Engineering. The responsiveness takes the form of continuous feedback of capability to the integrated team.

Taking into account the above concepts, Principle 1 is established as 'use a data-driven process'.

\subsubsection{Building from core capabilities}

The concepts that relate to 'build from core capabilities' are: read across to reduce uncertainty and support influence; and accelerate manufacturing planning activity.

\section{Read across to reduce uncertainty and support influence}

'Core' manufacturing capabilities are those that have a strong data-driven demonstration of capable standard production methods that are associated with a component family and standard design features.

Executing technical activities by building from core capabilities is beneficial to the quality of the solution. Proven capability and established technical expertise can be read across to the next NPI project. In the concept stage existing data associated with a standard method of manufacture for a component type is used to support concept evaluation and influence the design. Design Engineers are thus proactively front-loaded with 'production capable' features. If adhered to these help to ensure a production standard definition before the design concept has been finalised. In this way the project can enter the development stage (where change is costly to the project) with a viable concept. Manufacturing capability gaps 
to take action for improvement later in the project can also be revealed by matching core capability to design requirements.

\section{Accelerate manufacturing planning activity}

Carrying out technical activities by building from core capabilities is useful for supporting a flexible project plan. Effective existing solutions require limited iterations during the development stage.

The importance of core capabilities to aid planning of NPI is endorsed by the subject experts in consultations. At early project stages Manufacturing Engineers can anticipate and plan for the schedule of activities that will be part of the development stage, as well as identifying progressive release requirements. Predictable inputs such as these support flexibility; long lead time material and tooling orders for standard solutions are removed from the project critical path by decoupling reliance on novel definition. The need for production trials and testing is restrained where good process capability data exists. Furthermore, by reading across technical solutions and manufacturing evaluation completion technical activities can be accelerated.

Principle 2 is 'build from core capabilities'.

\subsubsection{Developing the standard}

The concepts that relate to 'develop the standard' are: align manufacturing capability improvements to support design requirements; and plan the resource to deliver manufacturing capability.

\section{Align manufacturing capability improvements to support design requirements}

In addition to agreeing core capabilities, it is important for ME and Design Engineering to agree a viable balance of innovation to help meet customer requirements. The focus for ME should be to invest in process capability improvement that is focussed onto a manageable number of important features that support the design. The importance of specific signals from Design Engineering for innovation in manufacturing capability that is important for the customer was proposed in the consultation phase. Core capabilities should be used to understand the specific signals regarding improvements to current production standards that will be valuable for the performance of the product. The resultant mix of core capabilities and development requirement should together maximise the available resources of the NPI 
project. In this way a capable process that also drives forward innovation with each generation of NPI project can be possible for the ME function.

\section{Plan the resource to deliver manufacturing capability}

There is a current focus using testing, prototyping and production trials in reaction to manufacturing process capability issues (or gaps) that emerge in the project. Detailed testing and analysis in the later development stages of NPI enables ME teams to better understand and quantify gaps in the capability of the process to support the design requirement. However, the increasing complexity of projects and shortening lead times are already making this approach difficult to achieve. Upfront engagement is necessary to obtain an early awareness of manufacturing capability and designer's need for innovation. In turn this is important for anticipating and planning the actions needed to enhance manufacturing capability that is viable for the current NPI project.

Virtual simulation tools are especially useful during the development stage and computer models are also used to produce rapid prototyping mock-ups. These serve to generate information feedback that influences both manufacturing and design development in a rapid manner requiring lower resource in comparison to full scale production trials.

Principle 3 is 'develop the standard'.

\subsubsection{Deliver through a responsive process}

The concepts that relate to 'delivering through responsive processes' are: taking action to maximise the use of incomplete design definition; and engaging in continuous evaluation and feedback.

\section{Maximising the use of partial and preliminary definition}

By taking action to maximise the use of incomplete design definition Manufacturing Engineers are enabling parallel design and manufacturing processes. This ability benefits from early cross-functional interaction. The expert consultation phase highlighted that by softening, or delaying the requirement of a final definition the Manufacturing Engineers offer greater opportunity for designers to better meet customer product requirements.

Working with partial definition and overcoming the dependency on completed design definition is the key ability that has been established by ME. The current practice investigation into NPI for aero engine components revealed a consistent strategy for using 
incomplete definition. This ranged from: using a concept definition in the early stage of the project (to understand the method of manufacture and clarify downstream planning needs); preliminary definition in later stages (to initiate long lead time activities and to model 'roughing' operations); and a final fixed definition (modelling 'finishing' operations, fixture tools, machine programmes and launching production).

Manufacturing Engineers are exploiting the toolset available to enhance what can be achieved with partial definition. A number of the tools have been demonstrated as the key resources for allowing responsive ME processes. A standard computer-aided system is the primary tool for delivering planning definition. Computer-aided tools help to concentrate the risk of using incomplete definition onto modelling tasks. These have low impact on resource and lead time in the project. The computer system is used to structure together the data that is relevant for how manufacturing processes are modelled. When linked, final revisions from the design model can be rapidly cascaded through to derivative definitions. This is used to manage update of all information to the correct design standard.

A culture of rapid iterations is also established on the use of virtual simulation and rapid prototyping. Again, these carry a limited burden in resource and time but can provide early and proactive insight into the impact of the design on the manufacturing process.

\section{Engage in continuous evaluation and feedback}

Concept and preliminary definition is important for driving evaluation of process capability, including Design for Manufacture assessments at early stages of the development project. In the development stage the later availability of feature-level information (in preliminary and fixed definitions) permits rigorous systematic manufacturing evaluation.

By supporting continuous evaluation and feedback using incomplete definition there is greater opportunity for risks to be proactively identified at early stages of the project lifecycle. This is useful for engaging with designers. The objective is a progressively agreed 'production standard' definition; this means manufacturing capability that is verified for all features and all risks addressed by ME.

Continuous evaluation and feedback serves to deliver a flawless production standard drawing without the burden of alterations late in the process. By accurately understanding risk ME teams have greater ability and confidence to manage the downstream planning using incomplete definition. 
Principle 4 is 'deliver through responsive processes'.

\subsubsection{Align cross-functional and customer requirements}

The concepts that relate to this factor are: upfront agreement; and ongoing management of requirements.

\section{Upfront agreement}

In the early concept stages of the project the priority should be agreeing the balance of core capabilities signals to indicate areas for manufacturing capability development. The integrated team is the best environment for $M E$ to receive and influence these signals that will impact how the NPI project will need to be carried out. By supporting the integrated team the Manufacturing Engineer representative ensures manufacturing requirements are coordinated with other functions.

It is necessary to engage with other functions, principally designers and external suppliers to ensure a viable plan for delivering a flawless production method. Furthermore, a close relationship with the representatives of other functions is useful for obtaining clear requirement signals. The data-driven process has helped to establish an equal level of understanding of design, manufacturing and customer requirements.

Upfront evaluation of the design concept (Design for Manufacture) is needed to agree a viable design concept. A viable concept balances customer requirements and can also be supported by a credible plan for design and manufacturing NPI processes. The key requirements of $\mathrm{ME}$ is determining a plan for progressive definition that will be needed to sustain parallel planning (supports lead times and process development) and to influence the level of risk in the design.

\section{On-going Management of Requirements}

It is necessary to review the alignment of requirements within the cross-functional team as knowledge about the product and component matures during the project. Actions to mitigate risks that emerge must be agreed and monitored by the team. Communication within the integrated team can be supported by co-location, direct visits between the functions and virtual communication methods. A predominantly quantitative or data-driven dialogue is conducive for both for in-person and virtual interaction. Email, telephone communication and shared network folders helped good communication to be maintained for dispersed teams. 
Principle 5 is 'align cross-functional and customer requirements'.

\subsubsection{Summary}

In summary, the five principles described in this paper guide the actions of the Manufacturing Engineer that are important at different stages of the product development lifecycle. The areas of the product development lifecycle that the principles can be aligned with are illustrated in Figure 3.

\section{Insert here:}

Figure 2 Principles for Aerospace Manufacturing Engineering New Product Introduction

Principle 1 and Principle 5 are applicable throughout a product development project. They are aspects of cross-functional working and can have a positive influence on concurrent activities. Principles 2, 3 and 4 are about concurrent working. Principle 2 is important in upfront stages of the development lifecycle. Principle 3 and Principle 4 are relevant later in the project. Their activities are directly influenced by prior decisions made in Principle 2.

\subsection{Validation}

A progressive form validation was used at different stages of the investigation, culminating with the final development of the above principles. Validation of case study results was completed in workshops with the host businesses. This was both quantified (specific to the data recorded) and qualified validation (specific to the accuracy of the process maps). The interpretation and conclusions taken from survey (including the system model) were verified with the main stakeholders of the research. To validate the interpretation of the factors and the principles, a series of semi-structured consultations with stakeholders in the research and subject experts in the business were conducted. Participants assessed how accurately the factors explained integrated NPI activity for ME. A total of 6 consultations were carried out. The validation process was continued until the factors and their description as guiding principles was considered complete.

\section{Conclusions}

This paper has presented an investigation of practices in Manufacturing Engineering that add value during New Product Introduction. The research has been conducted to address 
two gaps in the literature: how ME practices work together for integration; and the principles for successful ME in integrated NPI projects.

Elucidating the Manufacturing Engineering subject and the research gaps are novel contributions to the literature for lean product development. The literature lacked an understanding of how Manufacturing Engineers operate in integrated product development projects, including how partial definition is managed effectively.

A research strategy involving a mixture of methods has been used. This has provided both detail and breadth to the investigation which drew on the experience of aerospace component NPI for a range of examples in the industrial sponsor. The breadth is important; a diverse range of design and manufacturing challenges that influence how Manufacturing Engineers manage NPI were captured. In this way confidence that a good understanding of general practice was created.

The investigation demonstrates that $\mathrm{ME}$ is a complex objective to accomplish: multiple practices are used together to create value, overcome barriers to the flow of product development information and achieve cross-functional integration. It is important to align together practices that reside Process, Organisation, and Tool categories. This corresponds to the 'system' for lean product development that is identified recent literature in the domain.

The current practice is a foundation to strengthen in future projects. Cross-functional integration and parallel New Product Introduction processes have been important for enabling parallel ME. For the aerospace manufacturer that has sponsored this research these skills are either strongly established, or are a maturing experience achieved in recent product development projects.

The Principles for Aerospace Manufacturing Engineering indicate a vision for priorities in NPI projects. Whilst ME teams are developing crucial practices for operating parallel planning, they should also prioritise tasks to proactively reduce risk of significant change and focus on innovation that adds value to the customer. The principles focus on forging stronger links in the cross-functional to understand requirements, equip an ability to support innovation and demonstrate willingness to take on the responsive role that is necessary for flawless and innovative NPI. Further work will be necessary to verify the priorities and tasks that the principles indicate within the ME NPI process used in the business. 


\section{Acknowledgements}

The authors would like to thank the UK Engineering and Physical Sciences Research Council (EPSRC), the EngD Centre at Cranfield University and Rolls-Royce for supporting this work.

\section{Funding}

This work was supported by UK Engineering and Physical Sciences Research Council (EPSRC) EngD Centre at Cranfield University and Rolls-Royce.

\section{References}

1. Clark K.B., Fujimoto T., Product Development Performance: Strategy, Organization and Management in World Auto Industry, Harvard Business School Press, 1991.

2. Smart, P. K., Brookes, N. J., Lettice, F. E., Backhouse, C. J., and Burns, N. D. A boundary based view of product development: a feasibility study. Proc. Inst. Mech. Engrs, Part B: J. Engineering Manufacture, 2002, 216(B8), 1-12.

3. Morton, S. C., Brookes, N. J., Dainty, A. R. J., Backhouse, C. J. and Burns, N. D., The role of social relationships in improving product development decision making. Proc.IMechE, Part B: J. Engineering Manufacture, 2006, 220(6), 1017-1024.

4. Pennell, J. P. and Winner, R. I. Concurrent engineering: Practices and prospects. In: IEEE Global Telecommunications Conference \& Exhibition, 1989.

5. Hull, F. M. Composite forms of organization as a strategy for concurrent engineering effectiveness. IEEE Transactions on Engineering Manag., 1996, 43(2), 133-142.

6. Swift, K. G. and Brown, N. J. Implementation strategies for design for manufacture methodologies. Proc.IMechE, Part B: J. Engineering Manufacture, 2003, 217(6), 827833.

7. Hartley, J. R., Concurrent Engineering: Shortening Lead Times, Raising Quality, and Lowering Costs, Productivity Press, 1992. 
8. Patti, A.L., Gilbert, J.P., and Hartman, S. Physical co-location and the success of new product development projects. Engineering Management Journal, 1997, 9(3), 31

9. Smith, P. G. and Reinertsen, D. G, Developing Products in Half the Time. Van Nostrand Reinhold, 1991.

10. Wheelwright, S. C. and Clark, K. B. Revolutionizing Product Development: Quantum Leaps in Speed, Efficiency, and Quality, The Free Press - Simon \& Schuster, 1992.

11. Gerwin, D. and Moffat, L. Withdrawal of team autonomy during concurrent engineering. Management Science, 1997 43(9), 1275-1287.

12. Lakemond, N. and Berggren, C. Co-locating NPD? The need for combining project focus and organizational integration. Technovation, 2006, 26(7), 807-819.

13. Liker, J. K., Collins, P. D. and Hull, F. M. Flexibility and standardization: test of a contingency model of product design-manufacturing integration. J. Product Innovation Management, 1999, 16(3) 248-267.

14. Swink, M., and Nair, A. Capturing the competitive advantages of AMT: Designmanufacturing integration as a complementary asset. J. Operations Management, $2007,25,736-754$

15. Atkinson, D. and Al-Ashaab, A. A review and critical analysis of global new product introduction and development. Int. J. Product Development, 2008, 6(2) 118-141.

16. Baines, T. S. et al. State-of-the-art in lean design engineering: a literature review on white collar lean. Proc. IMechE, Part B: J. Engineering Manufacture, 2006, 220, 1599-1647.

17. Chase, J. Value Creation in the Product Development Process" Masters Thesis, Massachusetts Institute of Technology, Cambridge, USA, 2001.

18. Darwish M, Haque B, Shehab E, Al-Ashaab A. Value Stream Mapping and Analysis of Product Development (Engineering) Processes. In: ICMR International Conference on Manufacturing Research Durham University, 14-16 Sept 2010.

19. Pepe, C., Whitney, D., Henriques, E., Farndon, R., \& Moss, M. Development of a Framework for Improving Engineering Processes. In: ICED International Conference on Engineering Design, Copenhagen, 15-19 August 2011. 
20. Liker, J. K. and Morgan, J. M. The Toyota Way in Services: The Case of Lean Product Development, Acad. Manag. Perspect., 2006, 20(2), 5-20.

21. Haque, B. and James-Moore, M. Applying lean thinking to new product introduction. J. Engng Des., 2004, 15(1), 1-31.

22. Womack, J. P. and Jones, D. T. Lean thinking, 1996 (Simon \& Schuster).

23. Reinertsen, D. Let it flow. Ind. Engr, 2005, 37(6).

24. Maginness, M., Shehab, E., and Beadle, C. Value Stream Analysis of Manufacturing Engineering New Product Introduction Processes. In: ISPE International Conference on Concurrent Engineering, Boston, USA, July 4-8 2011.

25. Endris, K., Khan, M. S., and Arias, A. B. Advanced process planning in lean product and process development. In: ICE Conference on Engineering, Technology and Innovation, Munich, Germany, 10-18 June 2012.

26. Sobek II, D. K., Ward, A.C. and Liker, J. K. Toyota's principles of set-based concurrent engineering, Sloan Management Rev., 1999

27. Khan, M.S., Al-Ashaab, A., Shehab, E., Haque, B., Ewers, P., Sorli, M. and Sopelana, A. Towards lean product and process development. Int. J. Computer Integrated Manufacturing, 2011.

28. Khan, M; Al-Ashaab, A; Doultsinou, A; Shehab, E; Ewers, P; Sulowski, R. Set-Based Concurrent Engineering Within the LeanPPD Environment. In: ISPE International Conference on Concurrent Engineering, Boston, USA, July 4-8, 2011.

29. Creswell, J.W. Research Design: Qualitative, Quantitative, and Mixed Methods Approaches. 3rd ed, Sage Publications, 2007

30. Eisenhardt, K.M. Building Theories from Case Study Research. Acad. Manag. Rev., 1989, 14(4), 532-550

31. Yin, R. K. Case study research: design and methods, 1994 (Sage Publications). 


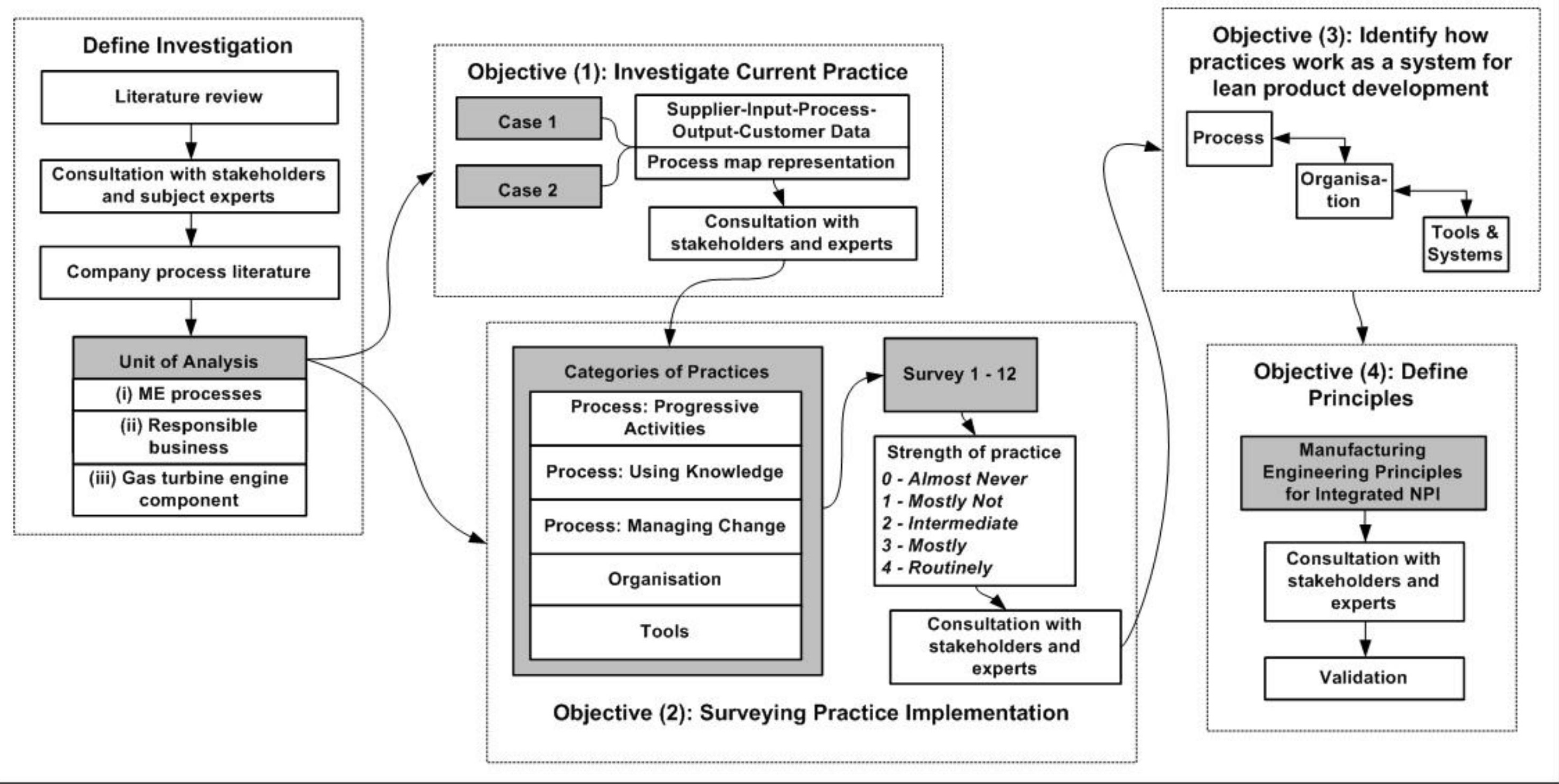


Lifecycle Stages:

Practice Categories

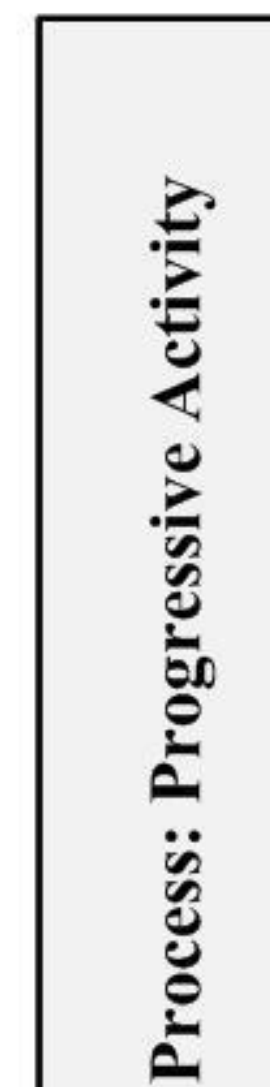

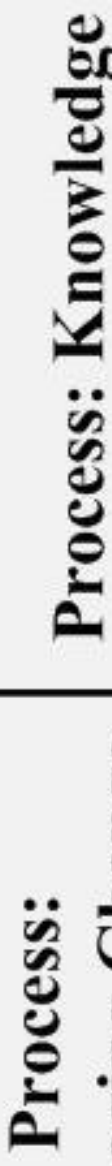

胥

\section{Manufacture \\ (operations list)}

- Schedule progressive release requirements (Manufacturing Launch Plan)

- Partial definition used for planning of

long lead time procurements
- Feature-leve

production and

inspection capability

data

- Component family

standards and

templates

- Production Standards
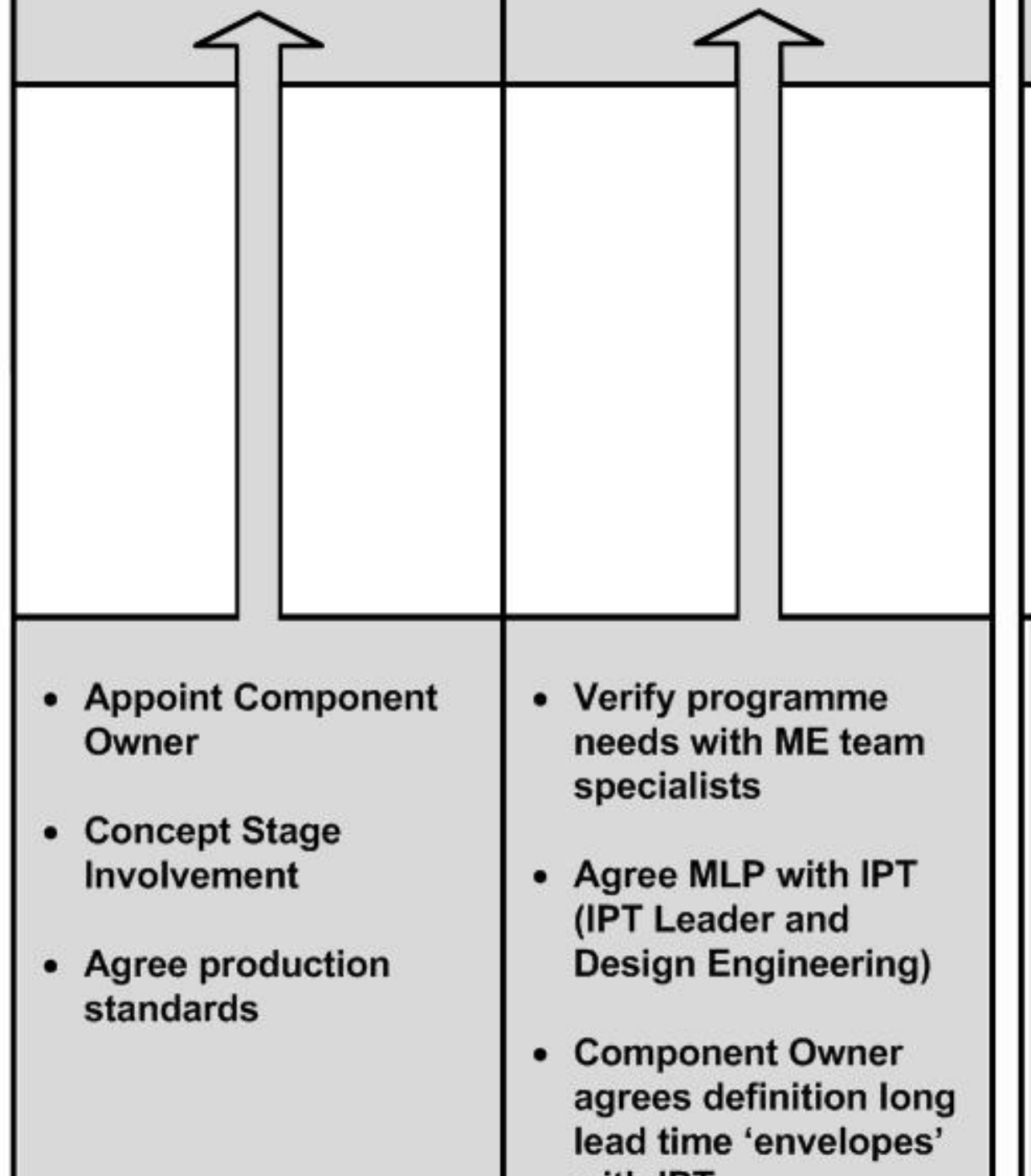

\section{- Agree production} standards Owner

- Concept Stage Involvement
- Appoint Component

\section{- Component family} standards and templates

- Production Standards

- Verify programme . specialists

- Agree MLP with IPT (IPT Leader and Design Engineering)

Component Owner agrees definition long lead time 'envelopes' with IPT

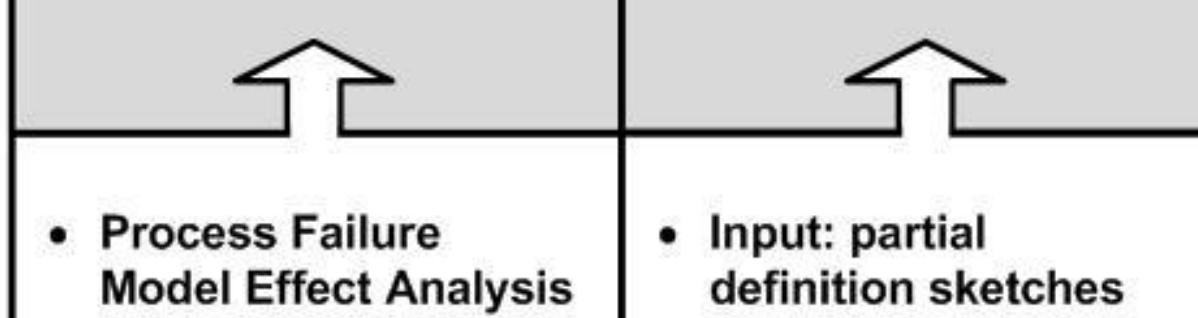

Model Effect Analysis (PFMEA)

- Dimensional

Characteristic Matrix and Feature

Verification Risk

Analysis (DCM \& FVRA)
Development Stage

\begin{tabular}{|c|c|}
\hline Build in Quality & Planning \\
\hline $\begin{array}{l}\text { - Evaluation and } \\
\text { acceptance of } \\
\text { definition release } \\
\text { using production and } \\
\text { inspection capability } \\
\text { data } \\
\text { - Update evaluation } \\
\text { tools to reflect } \\
\text { definition } \\
\text { - Test/trial activities to } \\
\text { close gaps }\end{array}$ & $\begin{array}{l}\text { - Create operation } \\
\text { stage models and } \\
\text { drawings; fixture and } \\
\text { machine tool } \\
\text { designs; CNC and } \\
\text { CMM }\end{array}$ \\
\hline $\begin{array}{l}\text { Feature-level } \\
\text { production and } \\
\text { inspection capability } \\
\text { data }\end{array}$ & $\begin{array}{l}\text { - Standard and } \\
\text { modular features }\end{array}$ \\
\hline
\end{tabular}

- Updating evaluation $\quad$ - Modifications to toolsets

- Build up capability data against definition standard geometry and NC sequences

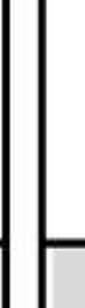

\begin{tabular}{|c|c|c|c|}
\hline $\begin{array}{l}\text { - Involvement with IPT } \\
\text { for progressive } \\
\text { evaluation } \\
\text { acceptance } \\
\text { - IPTL main conduit for } \\
\text { (including co- } \\
\text { location) } \\
\text { - Virtual IPT } \\
\text { communication }\end{array}$ & $\begin{array}{l}\text { Component Owner } \\
\text { pulls information and } \\
\text { fixed (stable) } \\
\text { definitions }\end{array}$ & & \\
\hline $\begin{array}{l}\text { - Input: sketches, } \\
\text { model or drawing } \\
\text { definitions }\end{array}$ & $\begin{array}{l}\text { - Input: checked status } \\
\text { models } \\
\text { - Use master model to } \\
\text { derive/link planning } \\
\text { models }\end{array}$ & $\begin{array}{l}\text { Dimensional } \\
\text { Characteristic Matrix } \\
\text { and Feature } \\
\text { Verification Risk } \\
\text { Analysis (DCM \& } \\
\text { FVRA) } \\
\text { - Process Failure Model } \\
\text { Effect Analysis } \\
\text { (PFMEA) }\end{array}$ & $\begin{array}{l}\text { - Linking model } \\
\text { creation/updating }\end{array}$ \\
\hline
\end{tabular}




\section{Principle 1: Use data-driven processes}

Support cross-functional understanding and decision making;

Capture and embed lessons.

Principle 2: Build from core capabilities

Read across to reduce uncertainty and support influence;

Accelerate manufacturing planning activity.
Principle 3: Develop the standard

Align manufacturing capability improvements to support design requirements;

Plan the resource to deliver manufacturing capability.

Taking action to maximise the use of incomplete design definition;

Engaging in continuous evaluation and feedback;

Principle 4: Deliver through responsive processes

\section{Upfront agreement;}

Ongoing management of requirements. 
2013-12-13

Principles for aerospace manufacturing engineering in integrated new product introduction

Maginness, Malachy

Sage

Maginness M, Shehab E, Beadle C, Carswell M. (2013) Principles for aerospace manufacturing engineering in integrated new product introduction, Proceedings of the Institution of Mechanical Engineers, Part B: Journal of Engineering Manufacture, Volume 228, Issue 7, pp. 801-810 http://dx.doi.org/10.1177/0954405413512811

Downloaded from Cranfield Library Services E-Repository 